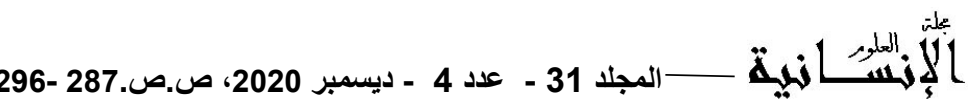

\title{
تطبيق نظرية السيادة في الاساتير الجزائرية
}

Application of the theory of sovereignty in the Algerian constitutions

تاريخ الاستلام : 2020/12/22 ؛ تاريخ القبول : 2021/01/03

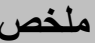

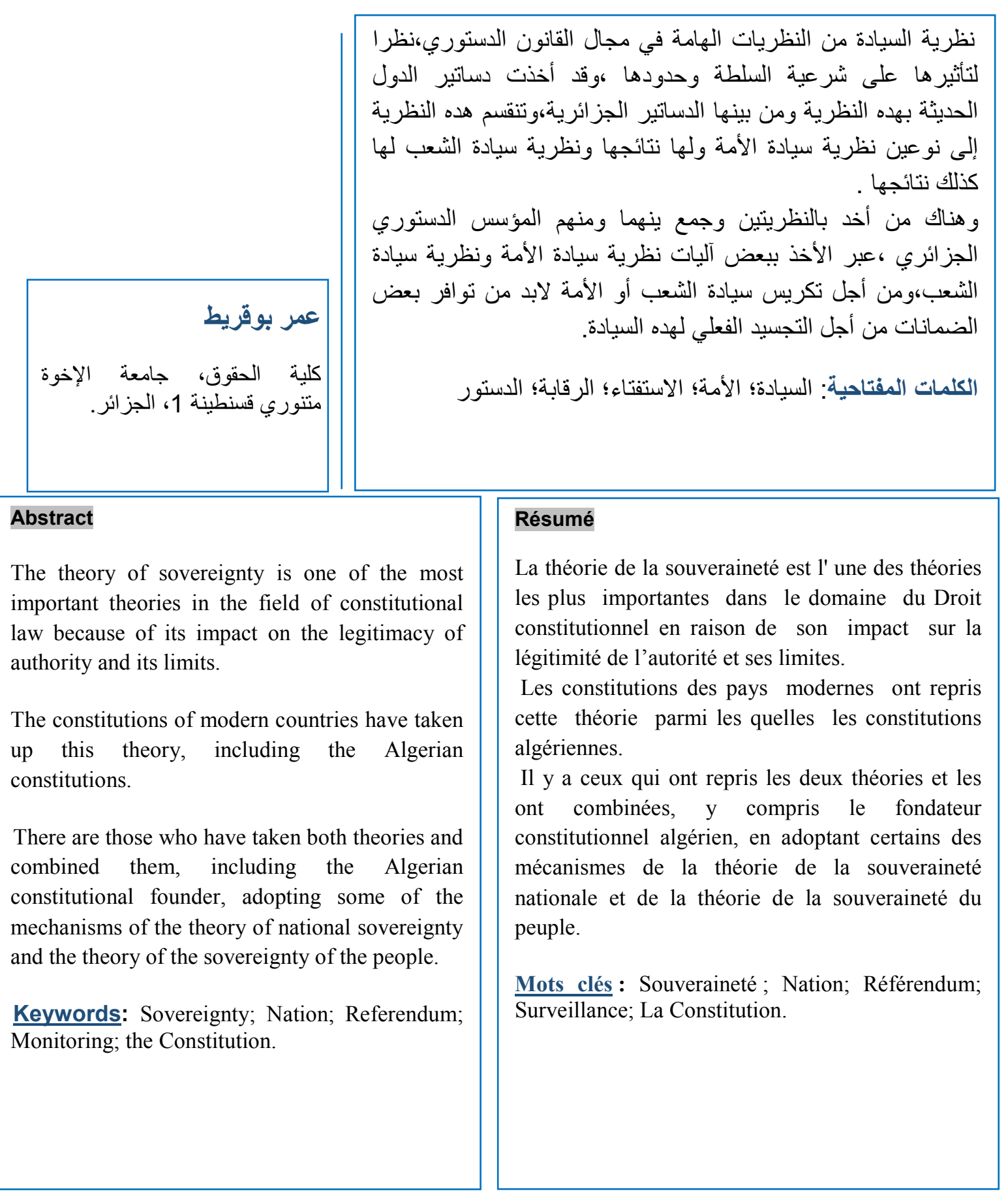

* Corresponding author, e-mail: authorC@mail.com

(؟) جامعة الاخوة منتوري قسنطينة 1، الجز ائر 2020. 


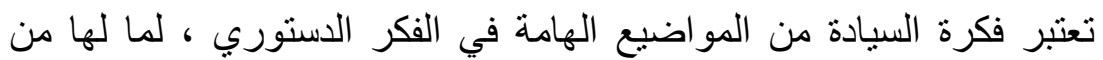

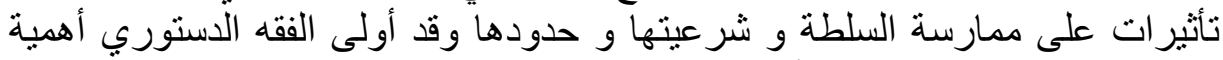

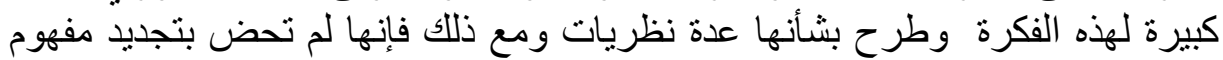

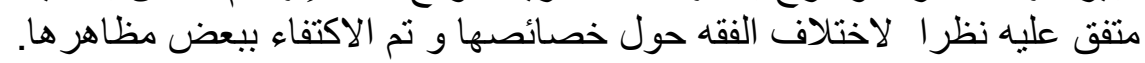

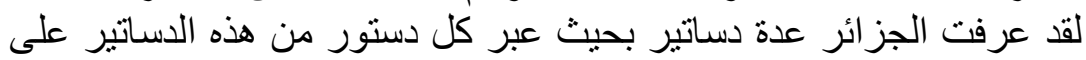

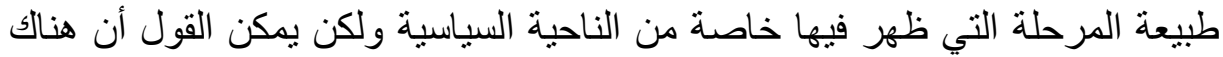

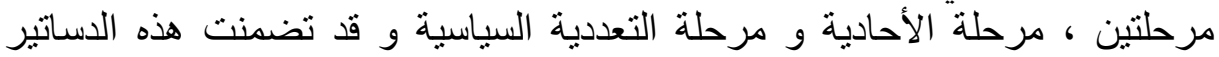

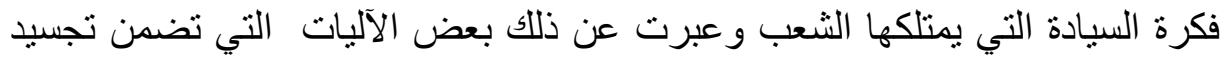

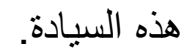
إن الجانب النظري لفكرة السيادة فيه الكثير من المفاهيم التي تشكل الإطار الفكري

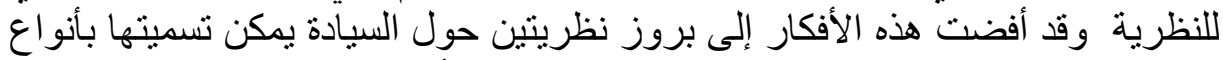

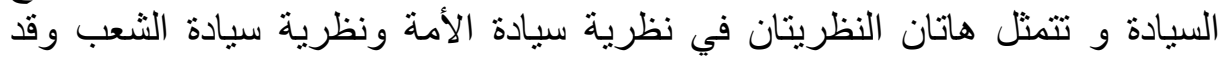

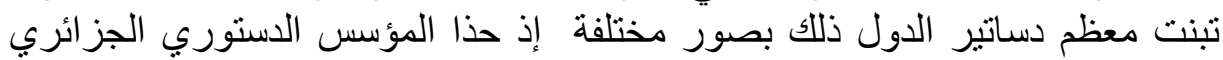
هذا النهج عبر الاساتير المختلفة.

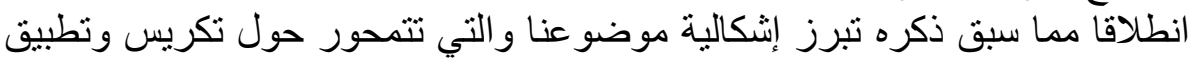

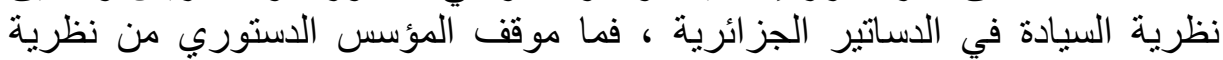

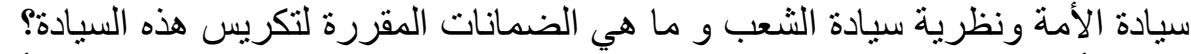

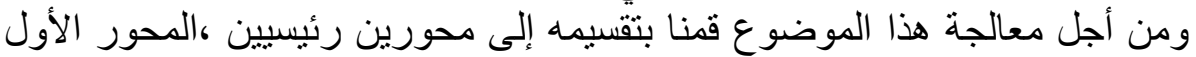

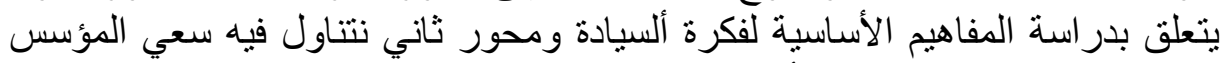

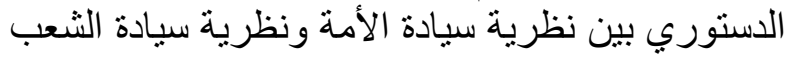

المحور الأول :المفاهيم الأساسية

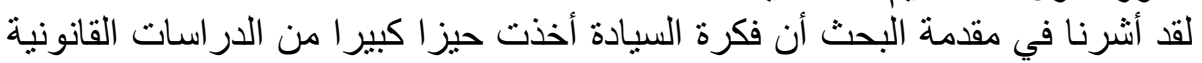

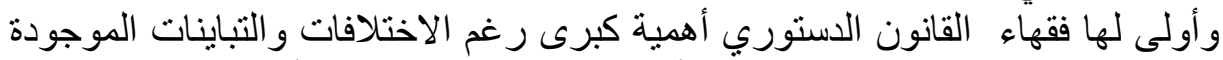

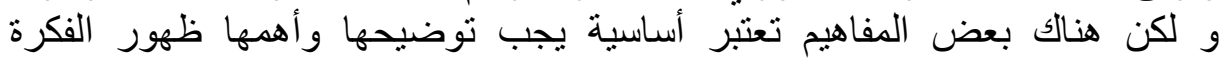

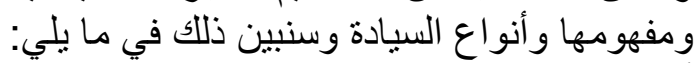
أولا : مفهوم فكرة السيادة أنوة النيادة أن تمييز الدولة عن غيرمه ها من التنظيمات والتجمعات ليس فقط بتو افر الأركان الثناثة

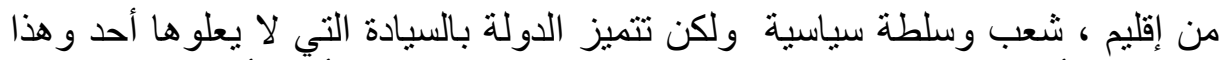

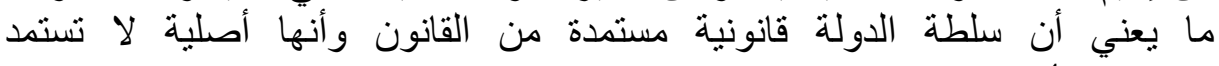
من غير ها 1.

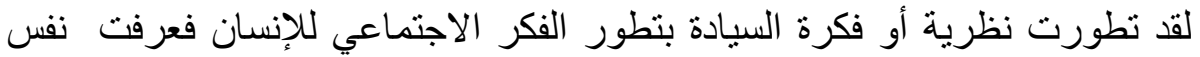

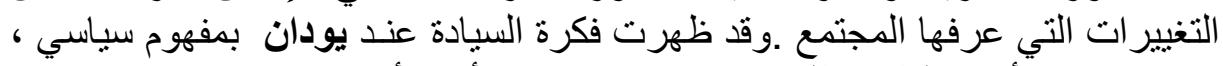

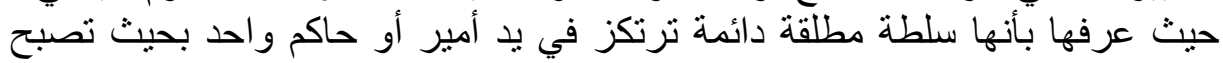

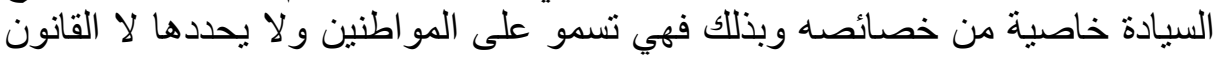
ورلا الدين وقد لخص يودادة خدان تعريفه في ثناثث نقاط:

لاستقلال إرادة الإنسان عن إرادة الله حيث تم رفض فكرة التأسيس الإلهي للسلطة. ل القانون الطبيعي هو الذي يحدد من هو صاحب السيادة ليس الدين وهذا ما

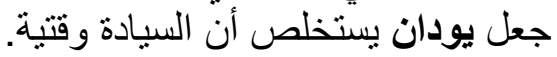
ح استقلال السياسة عن الدين. 
أما إيزمان فينطلق في تعريفه للسيادة من الدولة التي يرى بأنها تتخيص قانوني

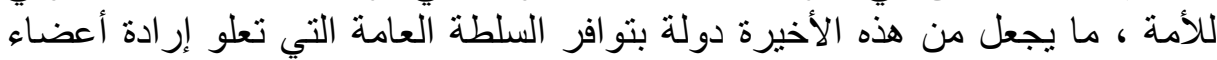

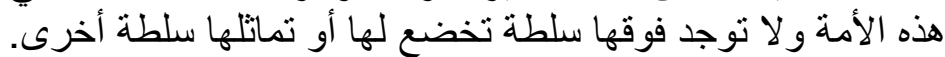

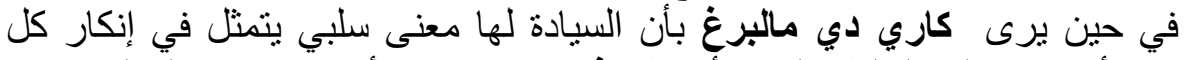

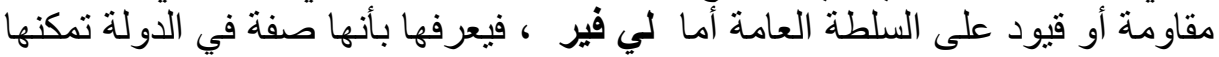

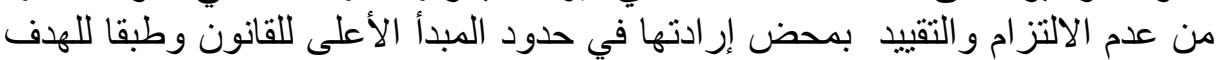
الجماعي الذي تأسست لتحقيقه. من جانبه يرى دابان أن الدولة تكون ذات سيادة في مواجهة الأفراد و الجماعات

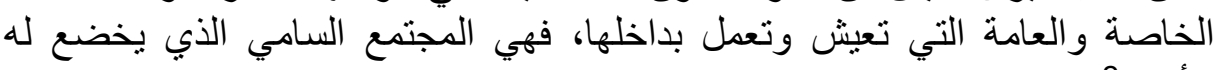

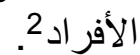

بناءا على ما سبق ذكره يتبين أن هناك تباين حول تحديد مفهوم السيادة ويرجع ذلك

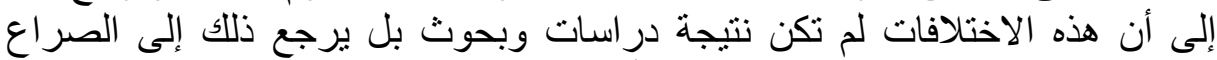

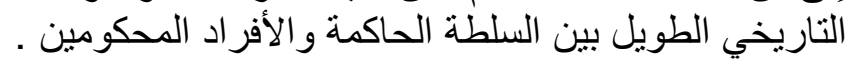
ومن أجلّ تبيان طبيعة ومضمون فكرة السيادة يجب الرجة الرجوع الركين إلى الأصل التاريخي لهذه

\section{ثانيا :الأصل التاريخي لفكرة السيادة}

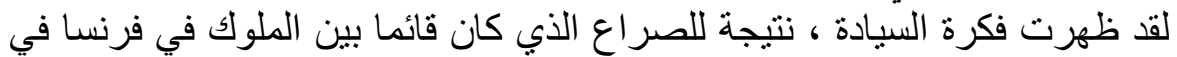

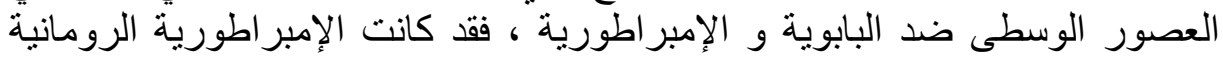

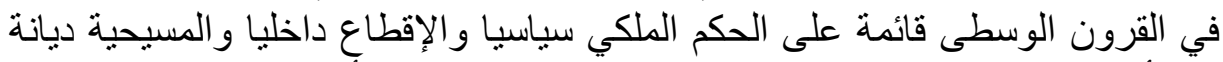

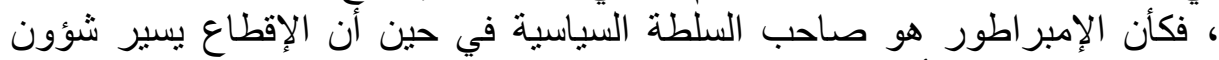

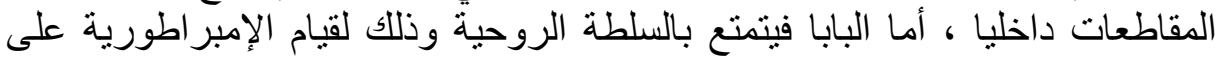

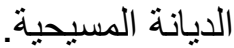

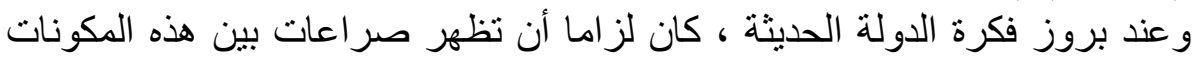

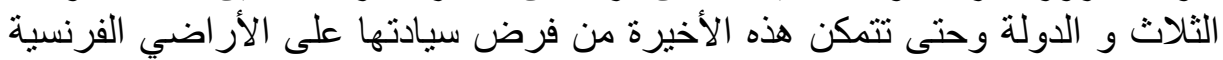

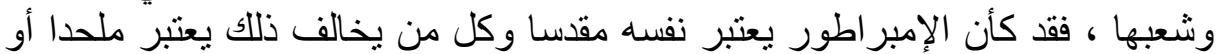

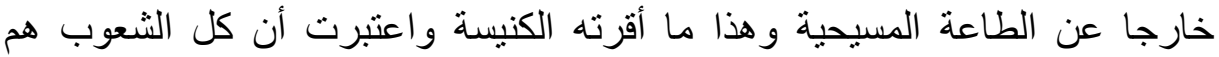

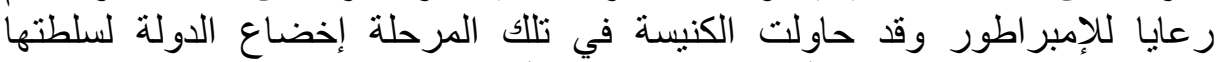

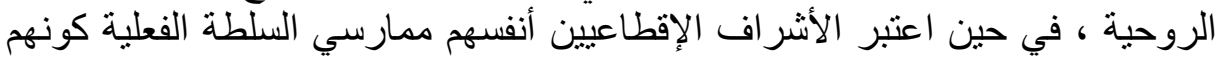

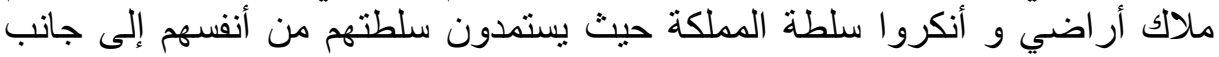

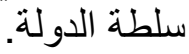

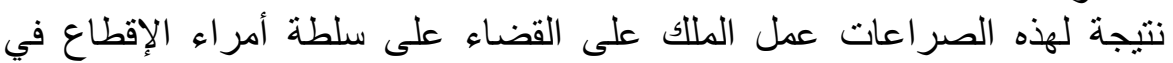

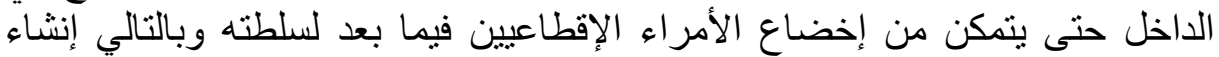

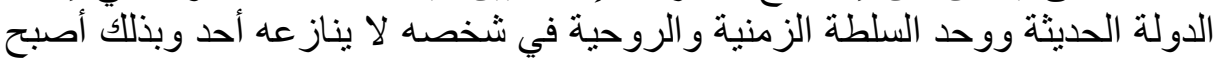

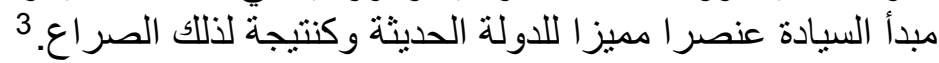

ثالثا أنواع السيادة أدى ظهور الدولة الحديثة والصراع العة الموجود بين الإمبر اطور من جهة و البرجو ازية

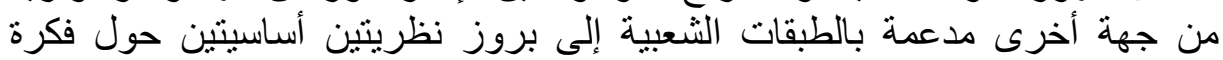

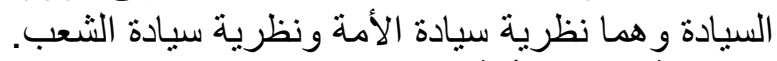

1

تعتبر هذه النظرية ذات أصل فرنسية تبنتها الثورة الفرنسية،متأثرة في ذلك بأفكار

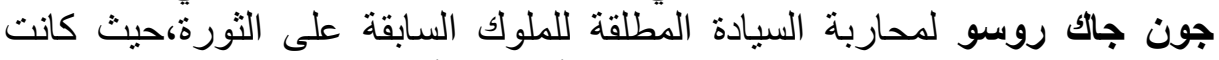

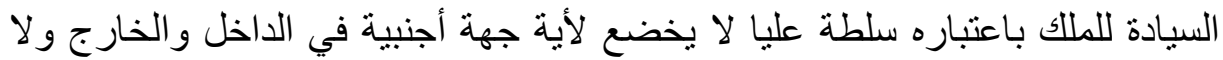


يوجد ما ينافسه في الداخل وجاءت الثورة وجعلت السيادة بما لها من صفات الإنات الإطلاق

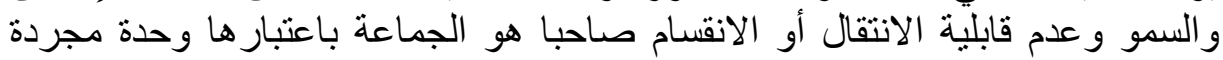

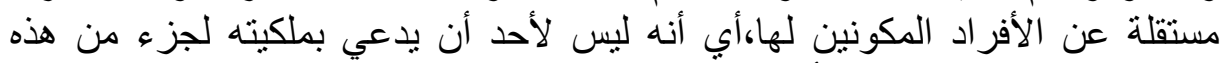

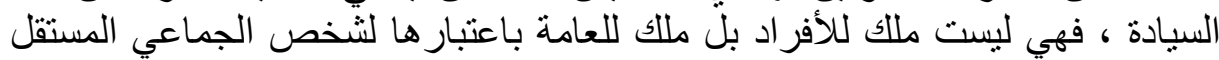
عن الأفر اد. 4

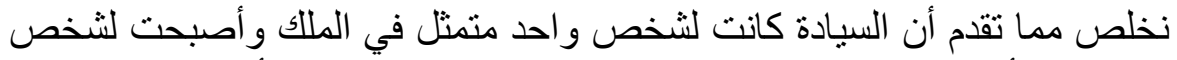

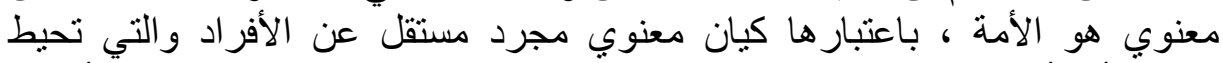

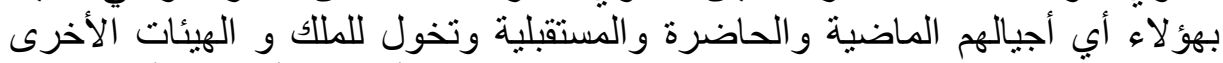

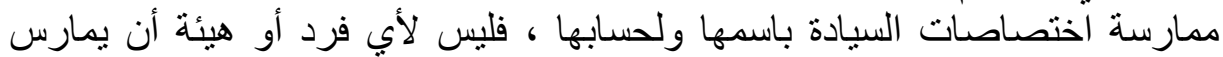

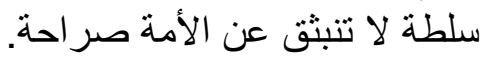

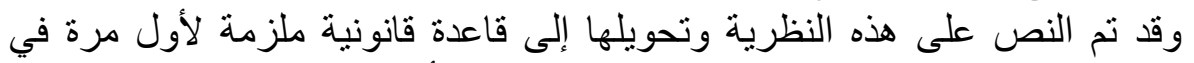

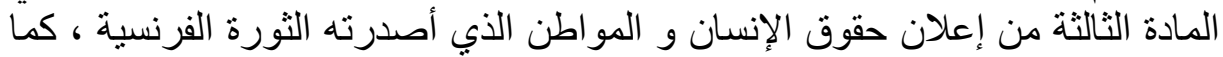

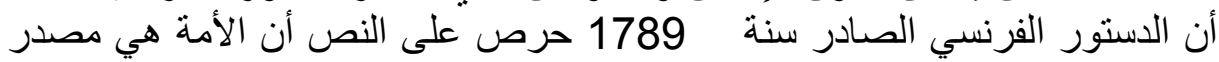

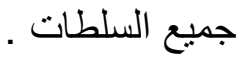

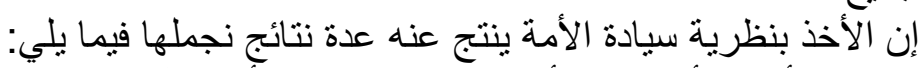

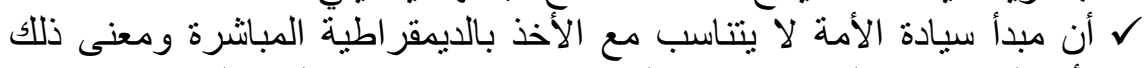

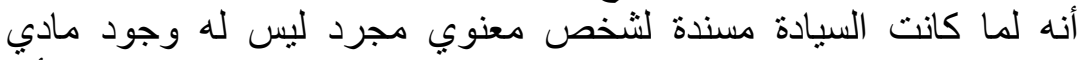

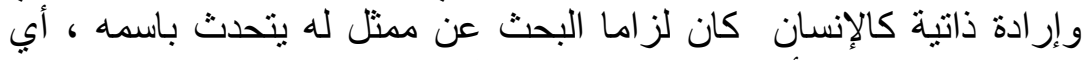

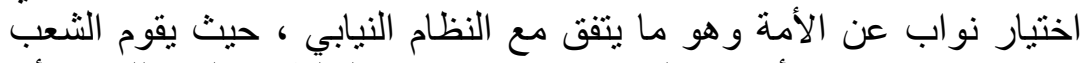

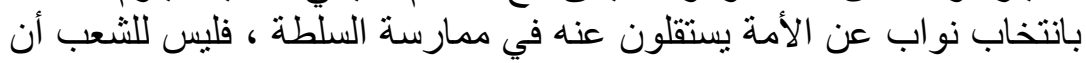

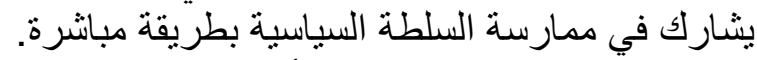

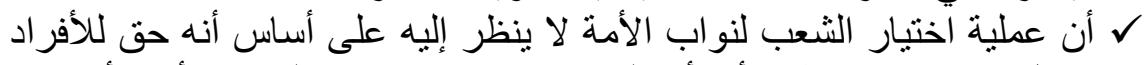

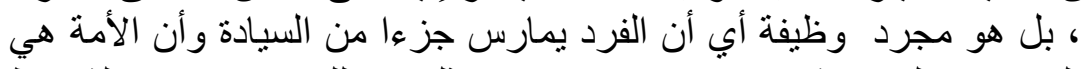

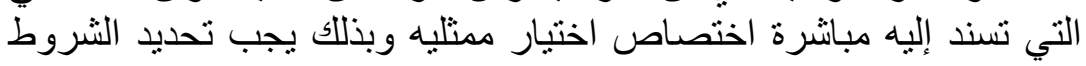

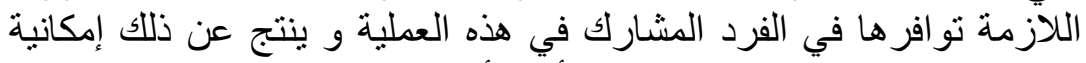

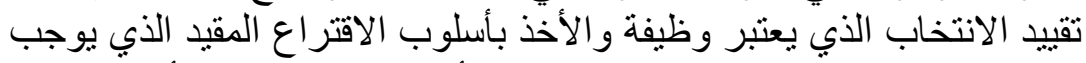

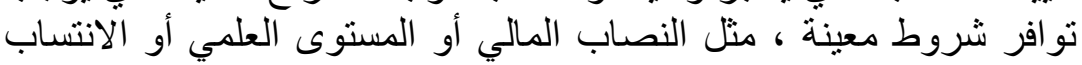

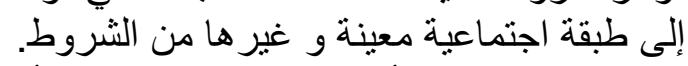

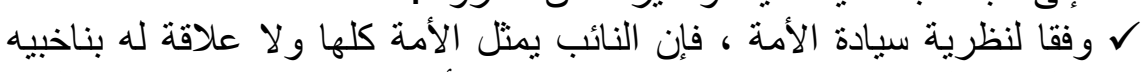

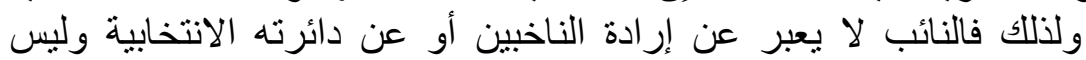

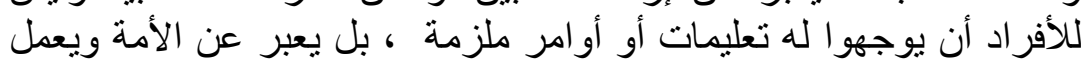
لصالحها.

إن الأخذ بنظرية الأمة سوف يؤثر على إرادة الأغلبية ولما كانت سيادة الأمة تعبر

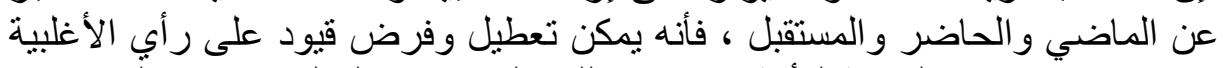

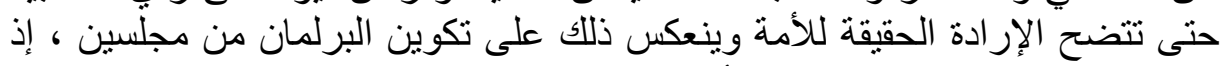

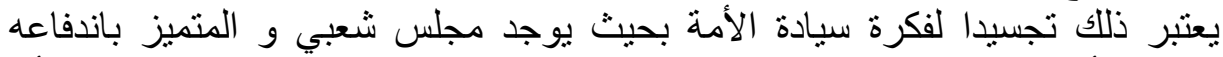

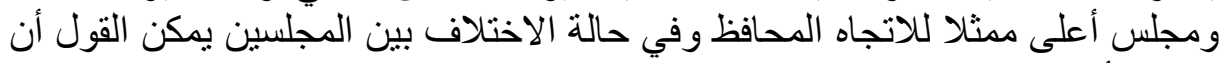

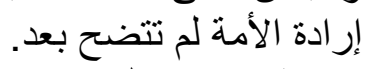

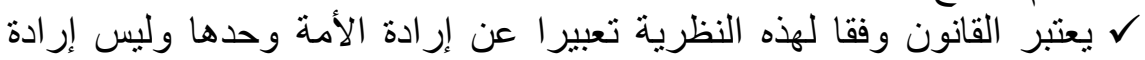

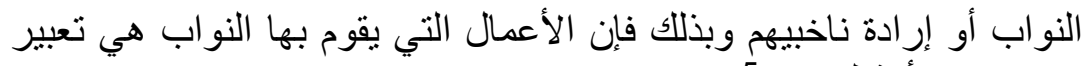

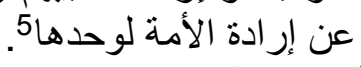
2 نظرية سيادة الشعب الثب لادب

تتمحور هذه النظرية عموما على أن الثعب هو صاحب السيادة ويبسط سلطته 


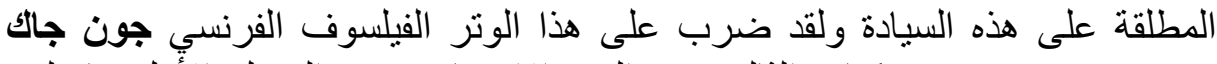
روسو حيث ورد في كتابه الثالث من العقد الاجتماعي في الفصل الأَّل ما يلي:

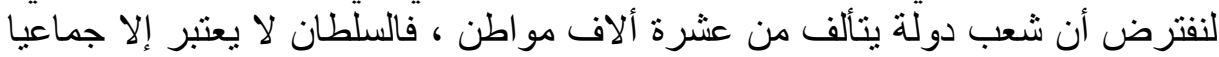

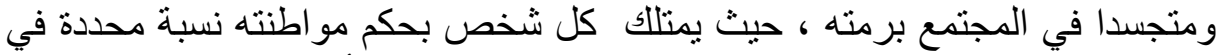
سلطة السيادة ، تقدر على وجه التحديد بواحد في عشرة ألاف ولو كان المواط الطن إخضع إلى سلطة السيادة.

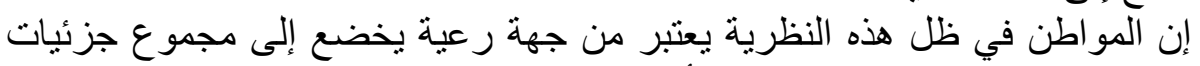

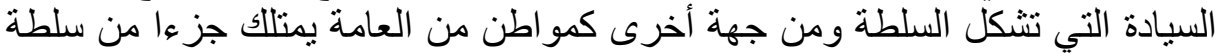

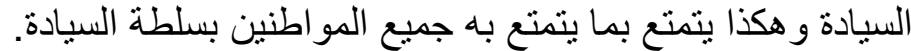

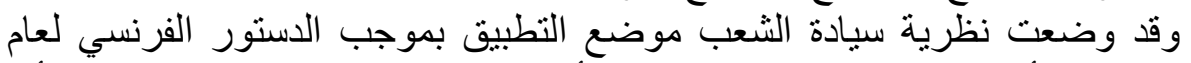

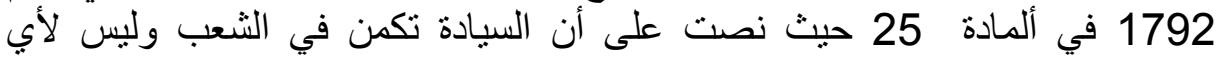

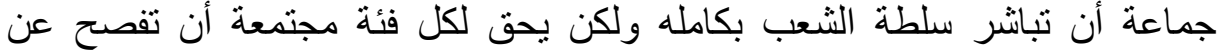

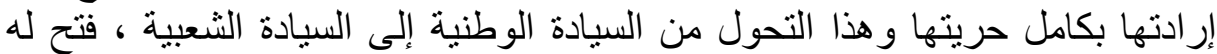

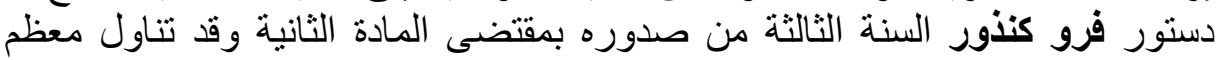

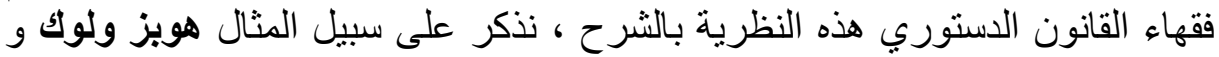
روسو وينتج عن هذه النظرية النتائج التالية:

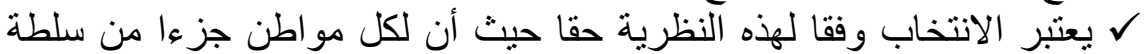

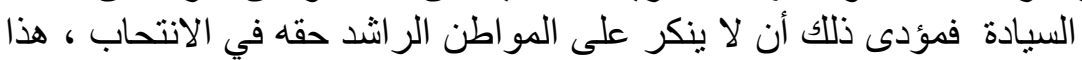

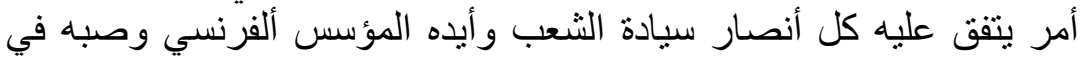

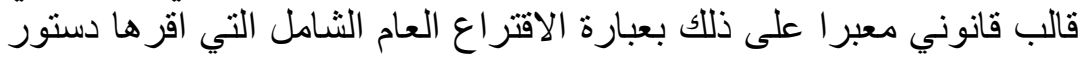

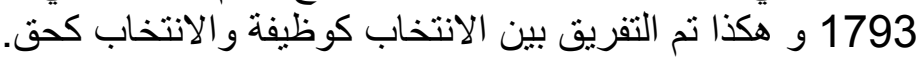

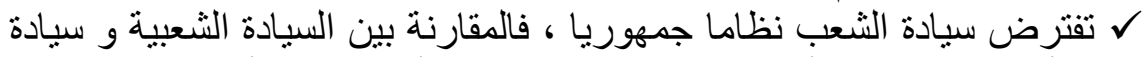

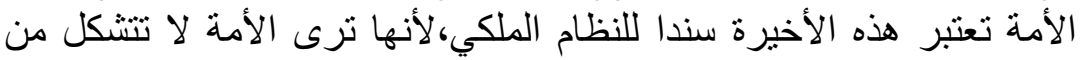

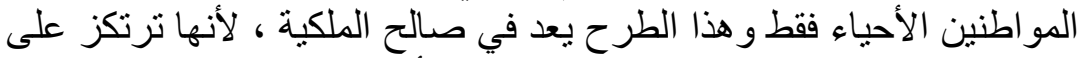

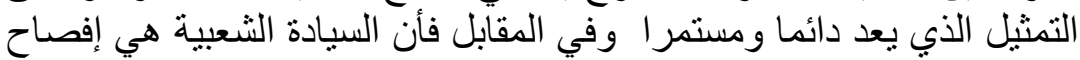

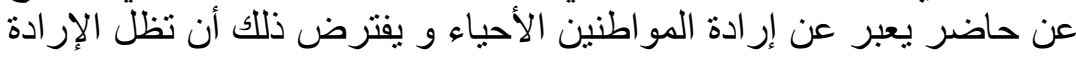

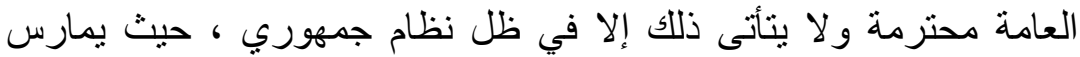

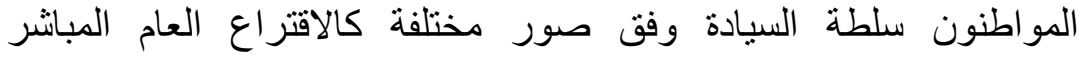
و والاستفتاء الثعبي.

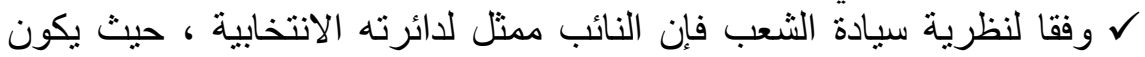

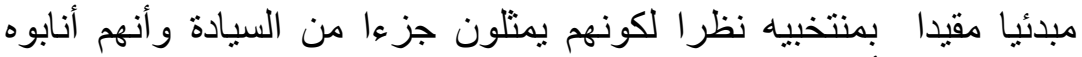

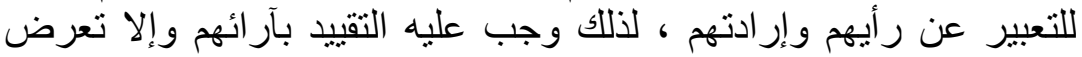

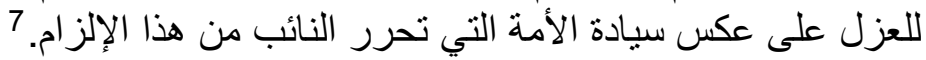
المحور الثاني:سعي المؤسس الاستوري بين النئين النظريتين

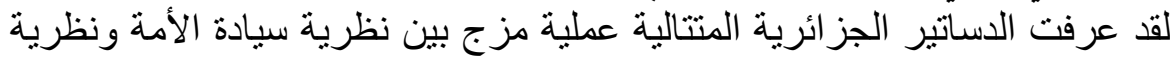

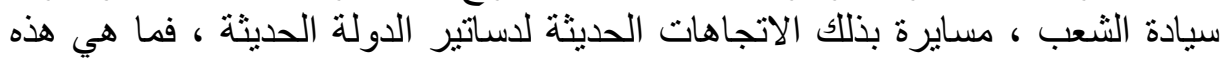

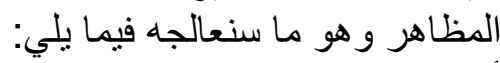
أولا: مظاهر المزج بين النظريتين

أخد الاستور بنظريه الأمة في المادة 27 لكنه خول الأنئ رئيس الجمهورية إمكانية

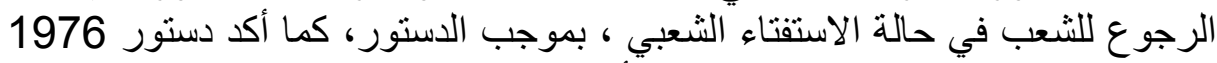

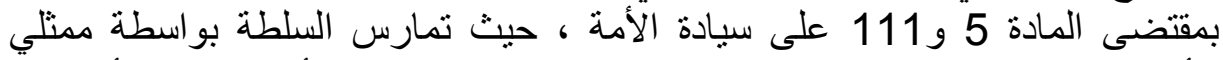

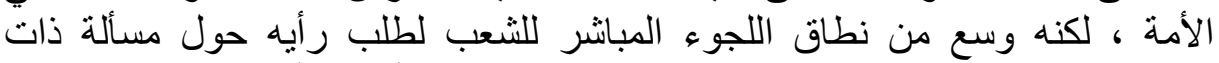

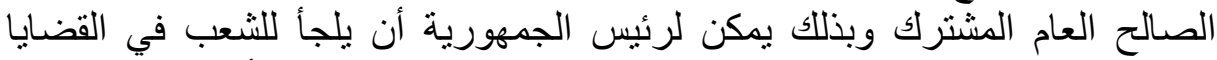

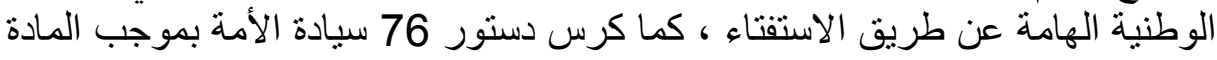
التاسعة وكذلك دستور 1996 في المادة 77 منه. 


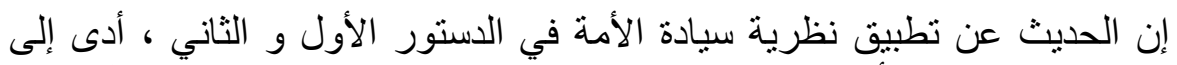

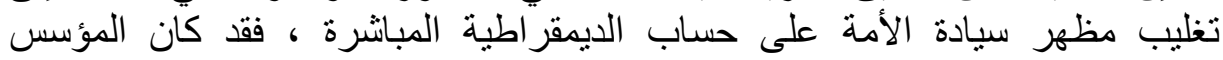

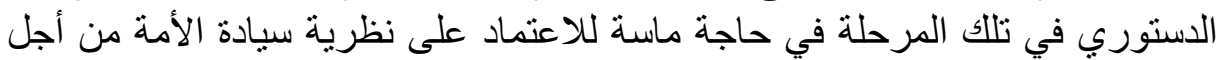

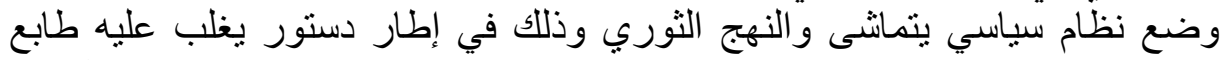

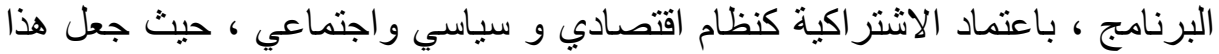

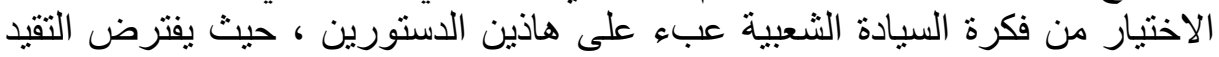

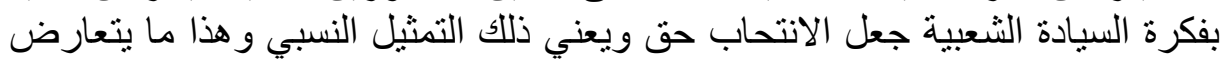

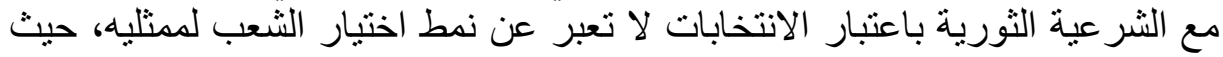

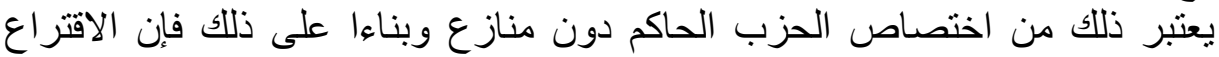

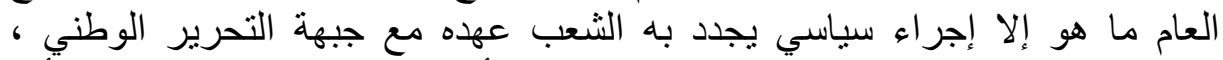

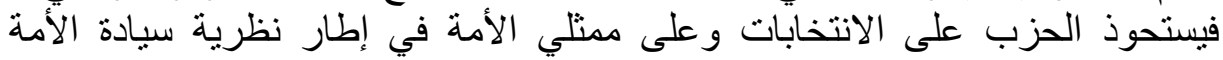
وينعكس ذللك على البرلمان.

بناءا على ما سبق ذكره يتبين أن المؤسن النس الدستوري في دستور 63 و و76 قد

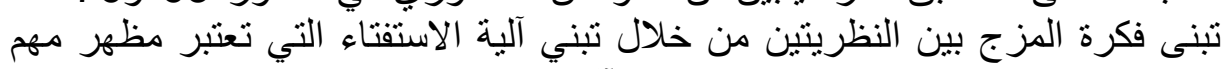

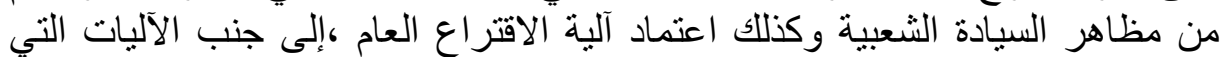

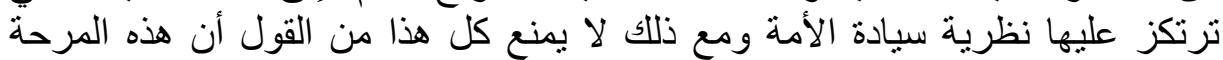
كانت الهيمنة لفكرة سيادة الأمة. إن المرحلة التي أعقبت مرحلة الأحادية السياسية قد بدأت بصدور دستور 89

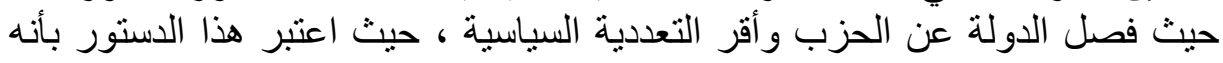

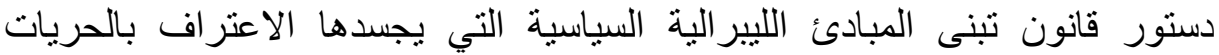

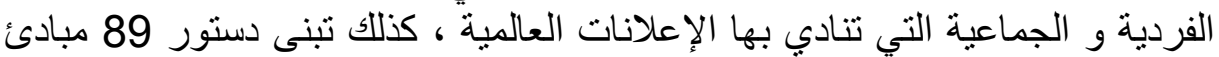

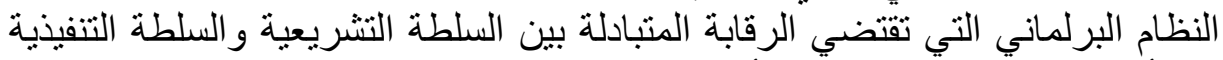

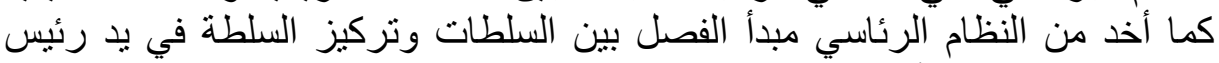

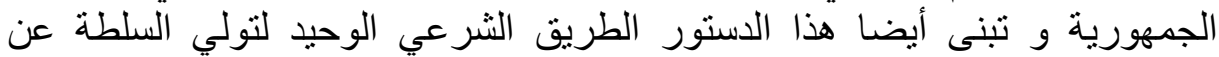

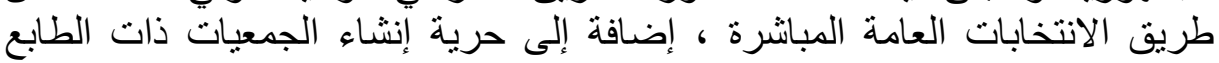
السياسي .

أما دستور 96 الذي يعتبر امتداد لدستور 89 فقد حافظ على نفس المبادئ

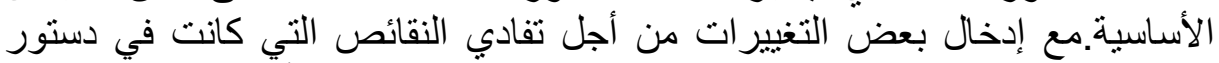

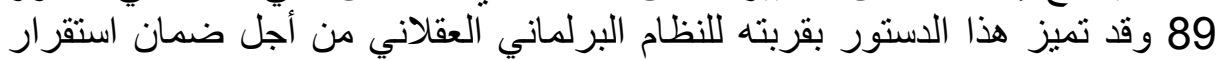

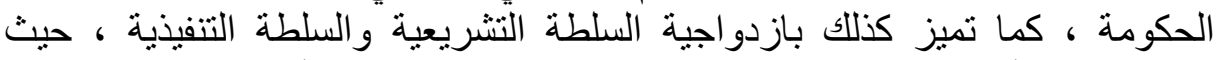

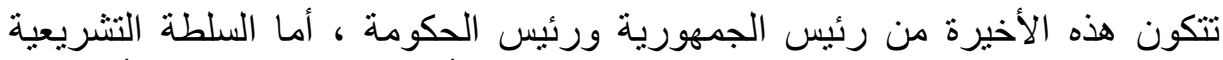

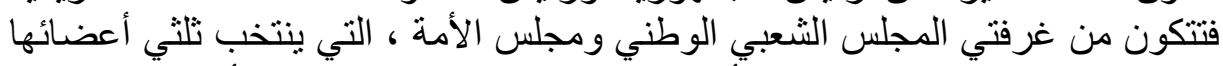

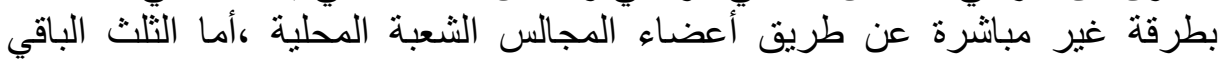

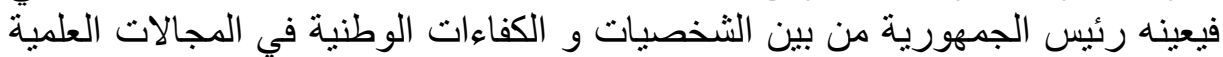
و الثقافية( المادة 110).

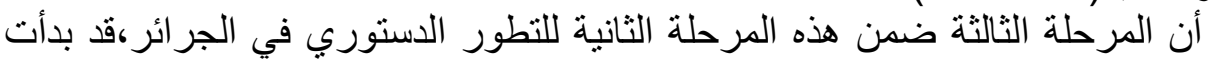

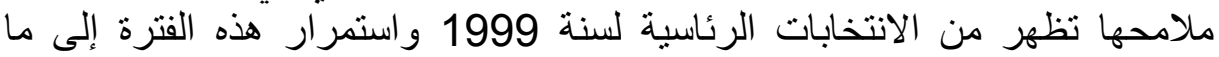

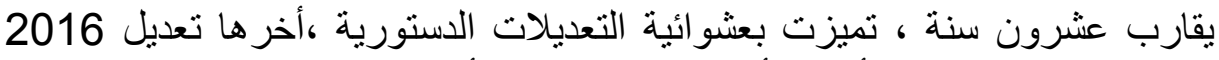

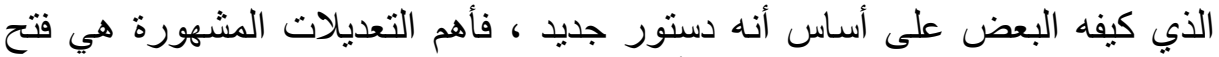

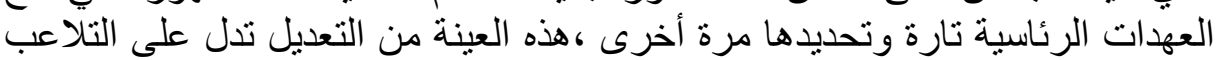

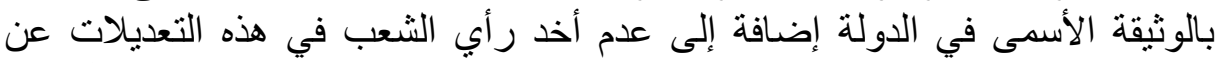

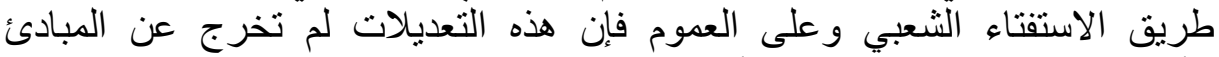

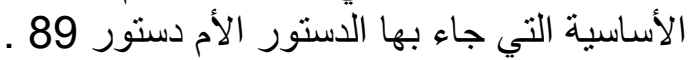


إن الانتقال من مرحلة الأحادية السياسية إلى مرحلة التعددية بداية بدستور 89

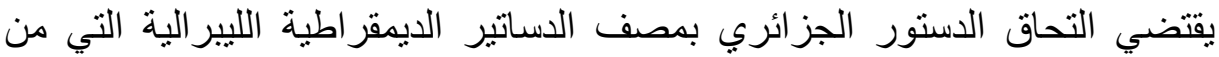

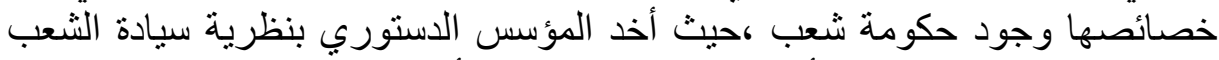

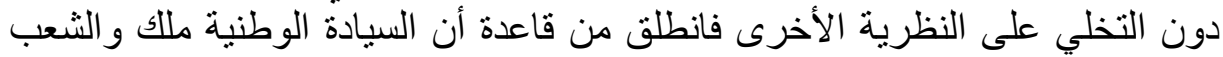

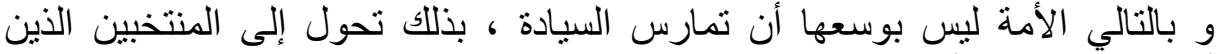

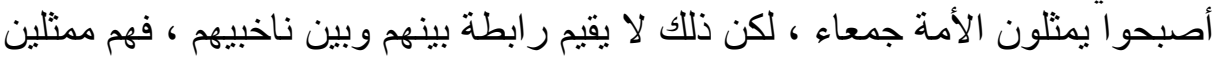

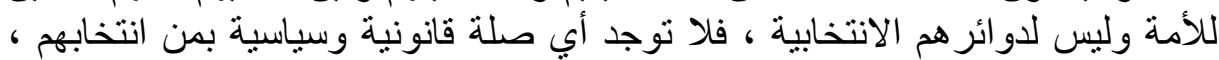

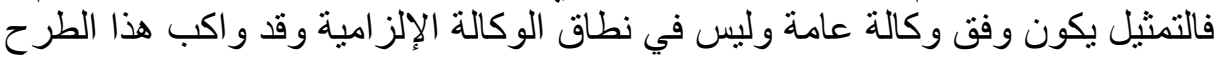

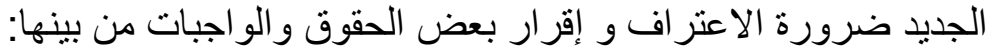

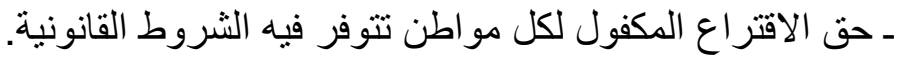

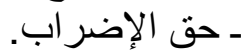

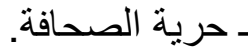
ـ حرية المعتقا. ـ حرية الصناعة و التجارة التهارة

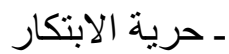

ثانيا : آليات ممارسة الثعب لسيادته وضماناتها

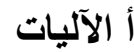

1 ـ الاستفتاء :أكد أغلب الفقهاء بأن الجسم التشريعي الذي يتكون من أفراد مميزين

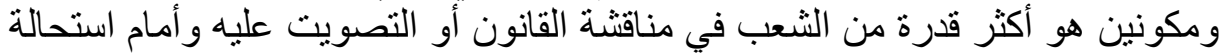

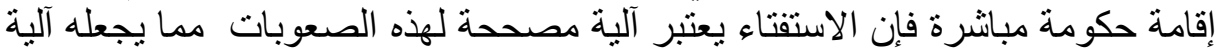

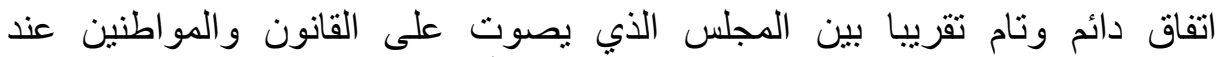
التصويت على القانون و بالتالي يتم التحقق من أن الإرادة الفردية مطابقة للإبرادة

ويعتبر الاستفتاء أخد لر أي الشعب حول موضوع ما داء ، حيث ينتوع إلى استفتاء

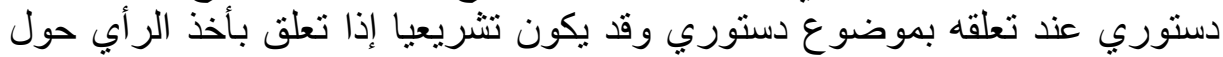

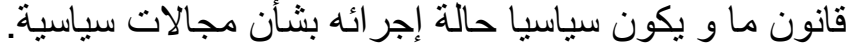

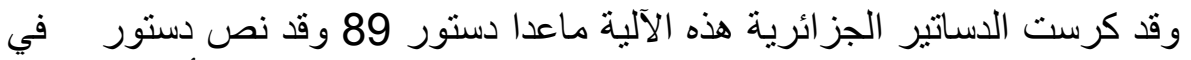

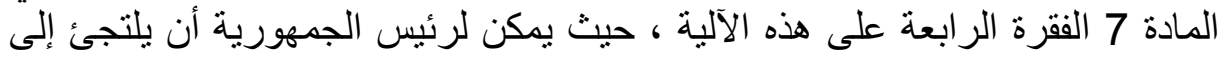

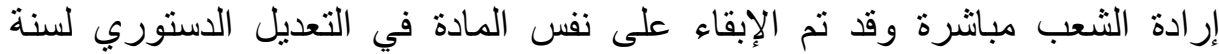
2016 و الجدير بالملاحظة في هذا الصدد أن قضية آلية الاستفتاء هي حق الإنة محفوظ

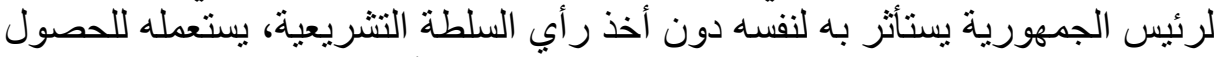

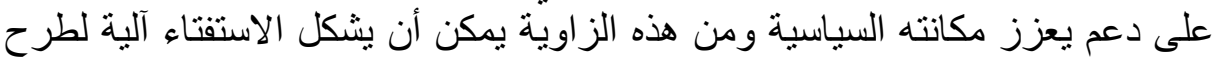

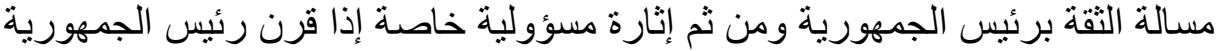

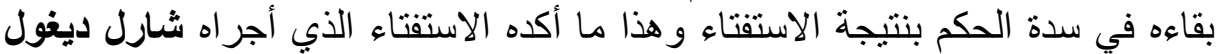

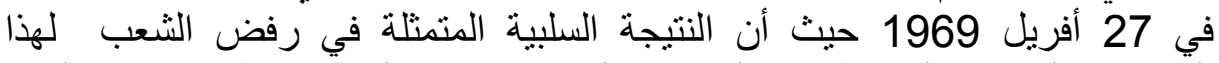
المشروع القانوني الذي طرح عليه كان السبب في استقالته إذ ربط بقائه في الحكم بنتيجة الاستفتاء 10.

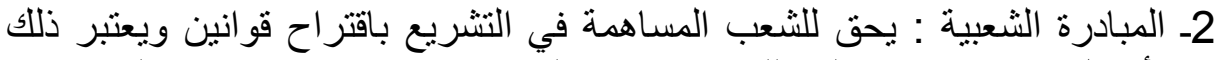

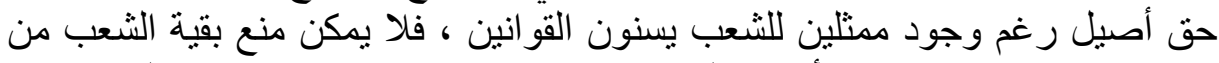

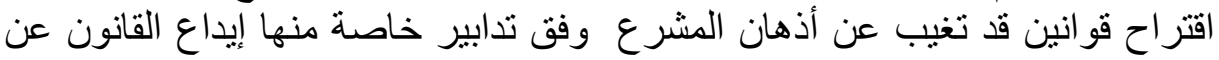

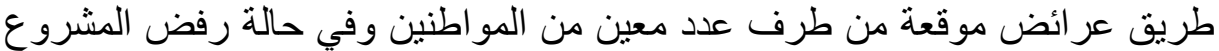

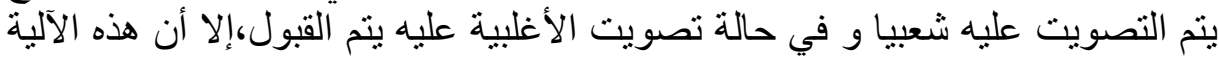
غير موجودة في الدساتير الجز ائرية. 3- انتخاب هيئات يختر ها الشعب :إن النية، السيادة الثعبية تقتضي مبدأ المساواة ،فكل 
الأفر اد متساوون فيما بينهم فلا يمكن لأي فرد الاستتاد على قانون طبيعي للوصول اللئه للسلطة بل يمارس السلطة من ينص عليه الدستور صراحة الدة وقد أكدت أغلب الدساتير

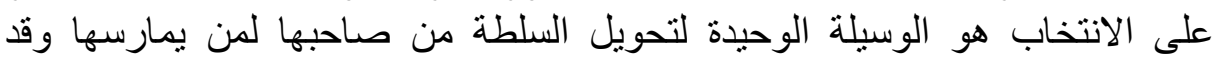
نصت الدساتير الجزائرية على آلية الانتخاب لتولي السلطة حسب طريقة لتبلة لتظيمها

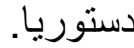

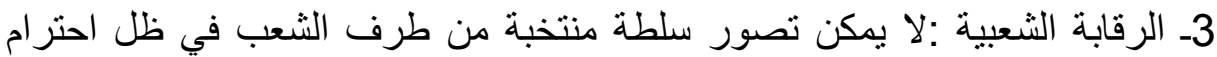

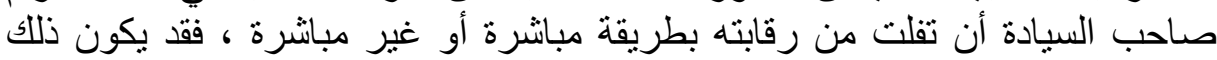
عن طريق الاعتر اض أو العزل أون أو الإقالة.

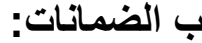

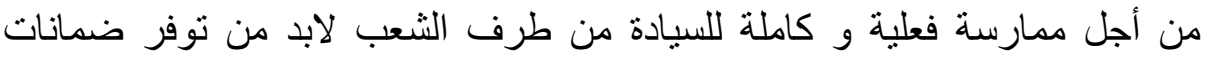

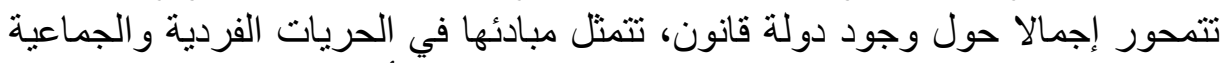

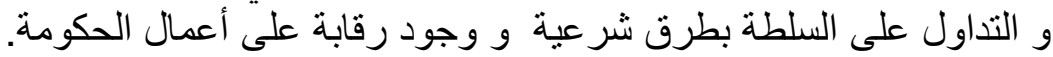

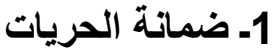

تقدس الديمقر اطيات الغربية الحرية التي يختلف مفهومها و و حدودها من نظام

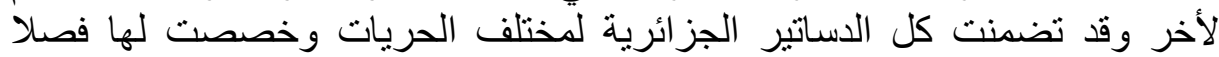
خاصا بها ، رغم اختلاف الأنظمة السياسية ، حيث نصت المادية المادة 12 من دستور 63

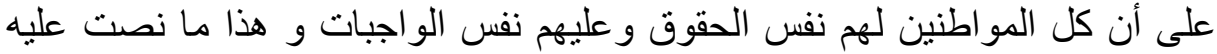

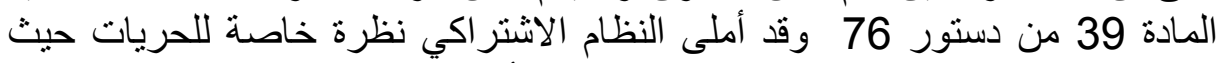

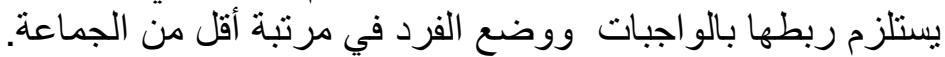

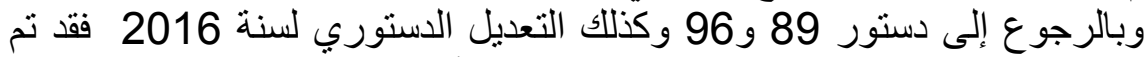

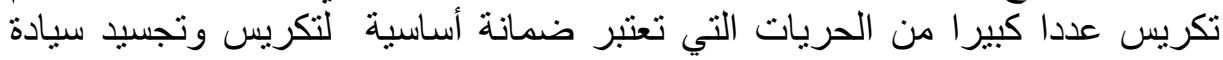

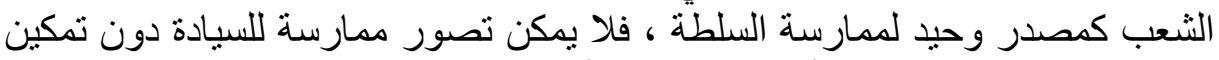

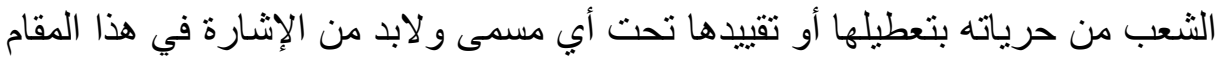

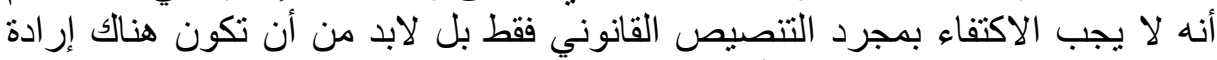

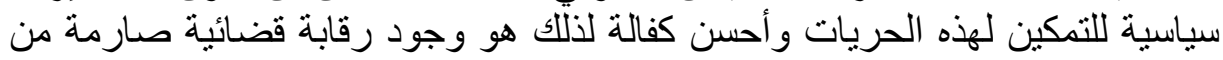

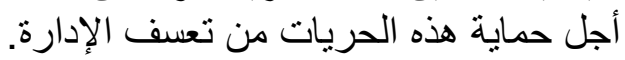

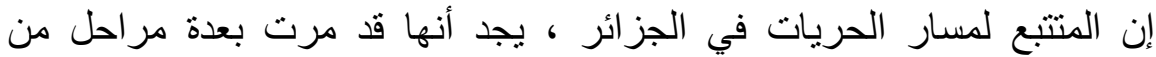

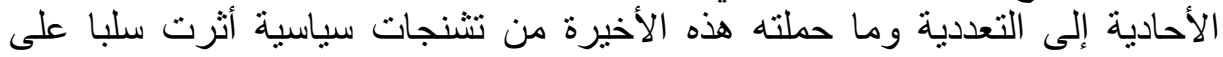

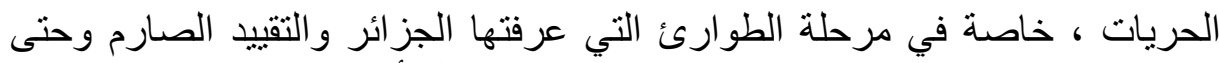

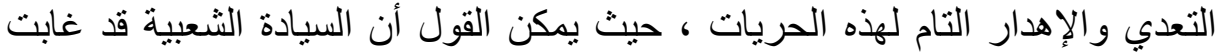

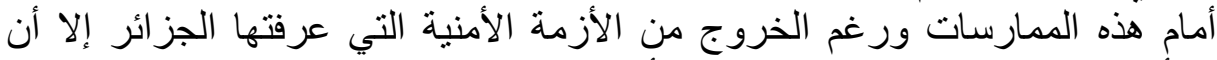

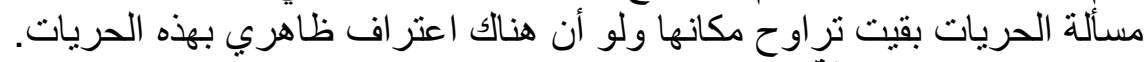

2- 2 - 2 التداول على السلطة

إن ضمان سيادة الثعب كمصدر الثبلة وحيد للسلطة بقتضي التداول على السلطة

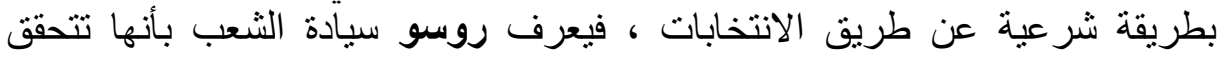

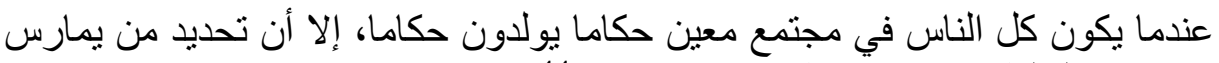
من بينهم السلطة يكون عن طرئن فئن الانتخابات. 11 وقد نصت الدساتير الجزائرية على وسيلة الانتخابات لتولي السلطة والتداول

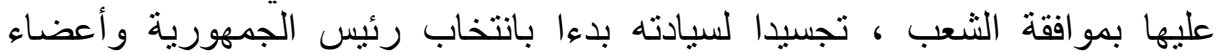
السلطة التشريعية وكذلك الجماعات المحلية ، كل هذا حسب طبية بليعة كل مرحلة و النظام الانتخابي المتبع. إن ضمانة التداول على السلطة بطريقة شرعية ، قد أسال الكثير من الحبر في

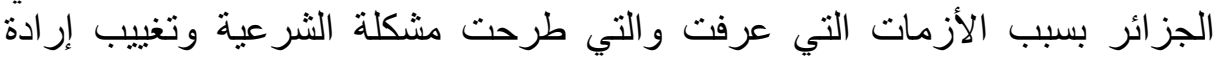


الثتب وسيادته ، فرغم اشتمال الدساتير الجزائرية على آلية الانتخاب لتولي السلطة

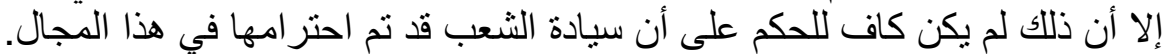

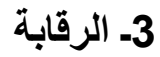

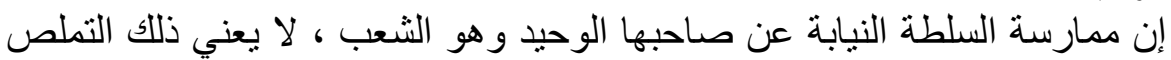

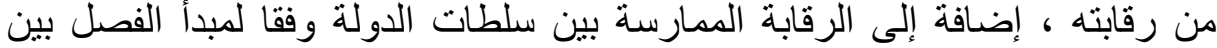
السلطات فهناك الرقابة الشعبية.

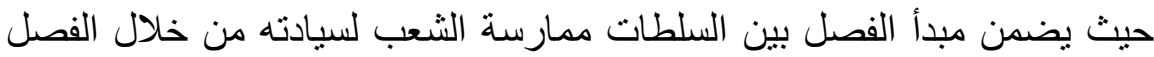

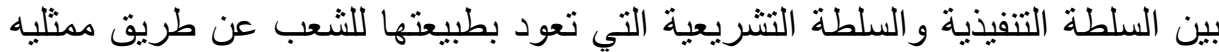
الذين ير اقبون مدى احتر ام المنفذين للإر ادة العامة ، كما يعني ذلك استقلالية التية القضاء عن السلطتين التنفيذية والتشريعية.

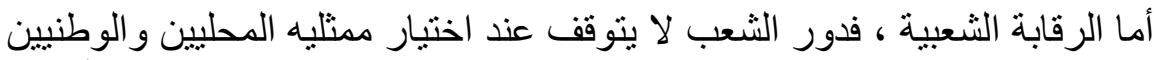

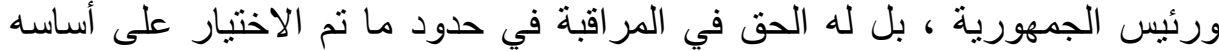
وتتحقق هذه الرقابة بطريقة قبلية عن طريق المشاركة في العملية الانتخابية كمراقبة

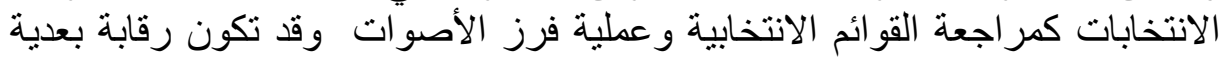

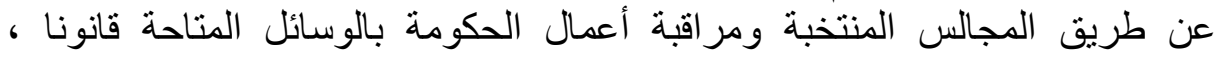
كالأسئلة الثفهية والمكتوبة وكذلك الاستجواب والتحقيق وكل هذه الوسائل قد تم النص عليها في الدساتير الجزائرية.

الخاتمة

لقد أعتمد المؤسس الدستوري الجزائري نظرية السيادة وطبقها في جميع الدساتير

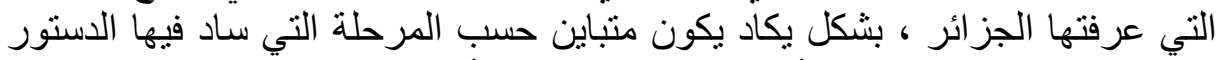

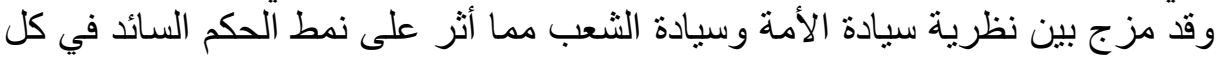

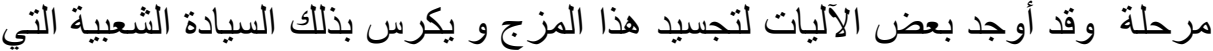
تعتبر الأصل الوحيد لتولي السلطة.

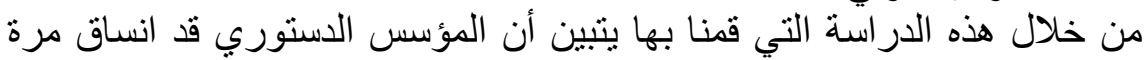

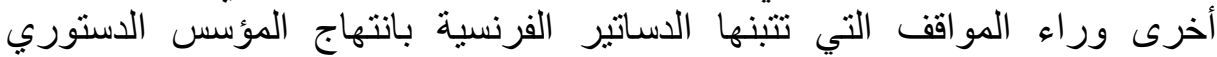

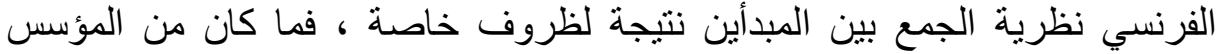

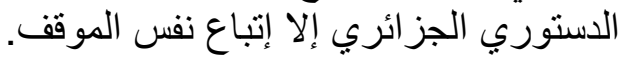

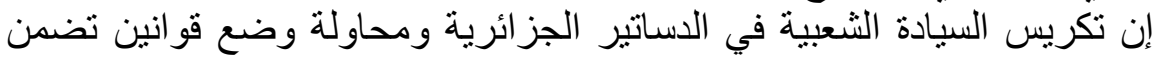

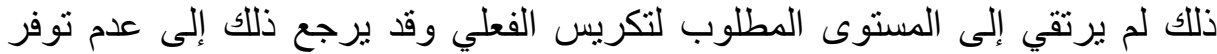

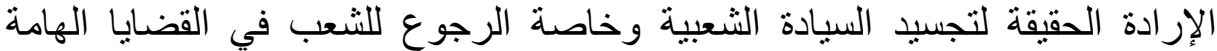

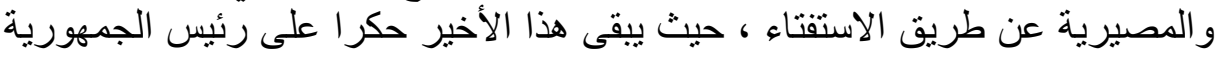

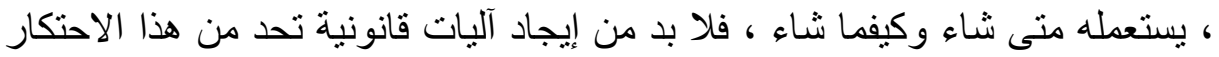
وتجسد فعليا آلية الاستفتاء. ت وكياء.

\section{ل الهوامش}

1 الجامعية،الجزائر،1988،صوأص8 و و شيحا إبراهيم مهنا ، مبادئ الأنظمة السياسية ، الدار الجامعية

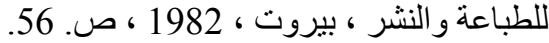

2 دلوش دلال ،السيادة الثعبية في النظام الدستوري الجزائري الحالي،رسالة ماجستير،جامعة الحاج

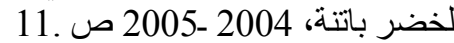

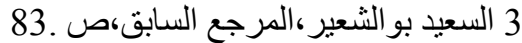

4 كسين محمد عثمان،النظم السياسية،ديوان المطبوعات الجامعية ، الإسكندرية ، 2001. ،ص 
5 نفس المرجع السابق،ص 45 و بوحوش عمار ، تطور النظريات والأنظمة السياسية ، الثركة

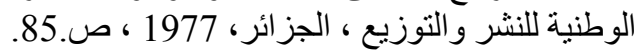

${ }^{6}$ Georges burdeau traité de science politique tome 6; 2 édition LGPJ Paris 1971 page 12 .

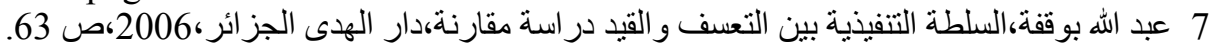

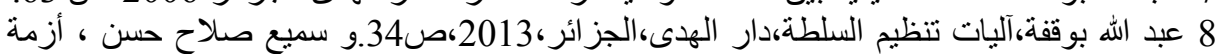

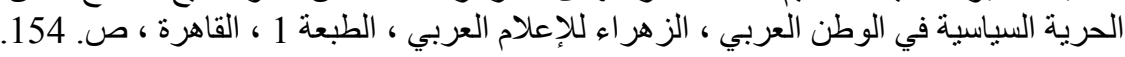
9 Maurice duverger, sociologie de la politique puf France édition 1; 1973 page 167.

10 عقيلة حرباثي،العلاقة الوظيفية بين الحكومة و البرلمان،دار الخلدونية،الجزائر،2007،ص 70

11 jean jacque rousseau, du contrat sociale, librairie générale francaise,paris,france, 1996,page7 . 